\title{
Avaliação da Atividade Antibacteriana de Dois Méis de Abelhas Indígenas Sem Ferrão Contra Bactérias de Importância Alimentar
}

\author{
Erick Kenji Nishio (I), Mariane Trizotti Krupiniski (I), Renata Katsuko \\ Takayama Kobayashi (I), Edson Aparecido Proni (I), Gerson \\ Nakazato (I) \\ (I) UEL - Universidade Estadual de Londrina (Rod Celso Garcia Cid Pr445 Km380 Cx Postal \\ 10011 Londrina PR)
}

\section{Resumo}

O mel é utilizado desde a antiguidade como alimento e considerado como parte da medicina tradicional. Os méis além de serem importantes pelas propriedades nutricionais destacam-se pelas propriedades funcionais e biológicas como atividade antioxidante, anti-inflamatória, antitumoral e antimicrobiana, podendo ser utilizado para a prevenção de doenças e promoção da saúde. As abelhas indígenas sem ferrão são nativas da região do Paraná e seus méis são bastante apreciados possuindo um preço de mercado superior ao mel de Apis. Neste estudo avaliamos a atividade antibacteriana de dois méis de abelhas indígenas sem ferrão contra bactérias de importância alimentar. Os méis de Scaptotrigona bipunctata (SB) e S. postica (SP), coletados na região de Londrina-PR e Mauá da Serra-PR foram diluídos em água destilada, esterilizados em filtro com poros de 0,22 $\mu \mathrm{m}$ e testados contra Staphylococcus aureus ATCC 25923, Enterococcus faecalis ATCC 29212, Escherichia. coli ATCC 25922 e Salmonella enterica sorovariedade Enteritidis ATCC 13076. Para a avaliação da atividade antibacteriana foram realizados os testes de poçodifusão em ágar e determinação da concentração inibitória mínima (CIM). Para a análise cinética do efeito antibacteriano foi construída uma curva de crescimento e morte. Para o mel SB, os diâmetros dos halos de inibição variaram entre 23 e $25 \mathrm{~mm}$, e a CIM foi de 0,62 e $1,25 \%$ para $\mathrm{S}$. aureus e

\footnotetext{
Referência:

Erick Kenji Nishio, Mariane Trizotti Krupiniski, Renata Katsuko Takayama Kobayashi, Edson Aparecido Proni, Gerson Nakazato. Avaliação da Atividade Antibacteriana de Dois Méis de Abelhas Indígenas Sem Ferrão Contra Bactérias de Importância Alimentar. In: Anais do 12을 Congresso Latinoamericano de Microbiologia e Higiene de Alimentos MICROAL 2014 [= Blucher Food Science Proceedings, num.1, vol.1]. São Paulo: Editora Blucher, 2014. DOI 10.5151/foodsci-microal-279
} 
E. faecalis, respectivamente. Para E. coli e S. Enteritidis, os halos de inibição variaram entre 14 e $25 \mathrm{~mm}$, respectivamente, e a CIM foi de $5 \%$ para ambas. Já para o mel SP, os halos de inibição variaram entre 22 e 28 $\mathrm{mm}$ para S. aureus e E. faecalis, respectivamente, e a CIM foi de 1,25\% para ambas. Já para E. coli e S. Enteritidis, os halos de inibição foram de 14 $\mathrm{mm}$ e CIM de $5 \%$ para ambas. Pela curva de crescimento e morte, pode-se observar eliminação total do crescimento bacteriano em $7 \mathrm{~h}$ de incubação para ambos os méis. Tais resultados comprovam que os méis de abelhas indígenas sem ferrão testados apresentam uma boa atividade antibacteriana ressaltando o benefício deste produto natural que pode ser utilizado como ingrediente para diferentes alimentos, além do possível uso para conservação de alimentos em substituição aos antimicrobianos comerciais que causam uma pressão seletiva, resultando no surgimento de microorganismos multirresistentes.

Palavras-Chave: Atividade antibacteriana, Abelhas indígenas, Mel Agência de Fomento: CAPES, UEL. 